\title{
Experimental Quantification of Metallurgy Changes Induced by Laser Welding in AISI304 Stainless Steel
}

\author{
Søren Heide Lambertsen ${ }^{1}$, Lars Damkilde ${ }^{1} \&$ Martin D. Ulriksen ${ }^{1}$ \\ ${ }^{1}$ Department of Structural Engineering, Aalborg University Esbjerg, Denmark \\ Correspondence: Søren Heide Lambertsen, Department of Structural Engineering, Aalborg University Esbjerg, Niels \\ Bohrs Vej 8, DK-6700 Esbjerg, Denmark
}

Received: April 30, 2014 Accepted: May 28, 2014 Available online: June 11, 2014

doi:10.11114/set.v1i2.437 URL: http://dx.doi.org/10.11114/set.v1i2.437

\begin{abstract}
Laser-welded joints of stainless steel AISI304 are investigated experimentally to determine the transfor- mation of austenite to martensite during the welding process. This transformation, which occurs in the welded region due to heating and residual stresses, can influence the fatigue and fracture properties of the affected material. Therefore, the scope of the present study is to determine the quantity of introduced martensite in the welded region and hereby clarify the influence of laser welding on the fatigue and fracture properties of welded AISI304 joints. The quantification of martensite concentration is carried out by use of four different methods, namely Lichtenegger and Bloech (LB1) etching, Ferritescope, X-ray diffraction (XRD), and Vickers hardness. It is found that a concentration of 1-1.6\% martensite is introduced in the laser-welded area; a quantity that has insignificant influence on the fatigue properties of the joints.
\end{abstract}

Keywords: Metallurgical transformation, Martensitic phase, AISI304, Laser-welded joints.

\section{Introduction}

In the constant attempt to optimize the employment of joints in steel structures, various welding methods have been developed since the Second World War. One of these methods is laser welding in which the heat source yielding the melting process is generated by a laser beam. This specific welding method has a major advantage compared to other methods, as it facilitates the joining of plates in several configurations ( $\mathrm{Li}$ et al., 2014). For instance, the keyhole technique (Li et al., 2014) makes it possible to weld perpendicular plates in one process (Morteza et al., 2007). This is illustrated in figure. 1 .

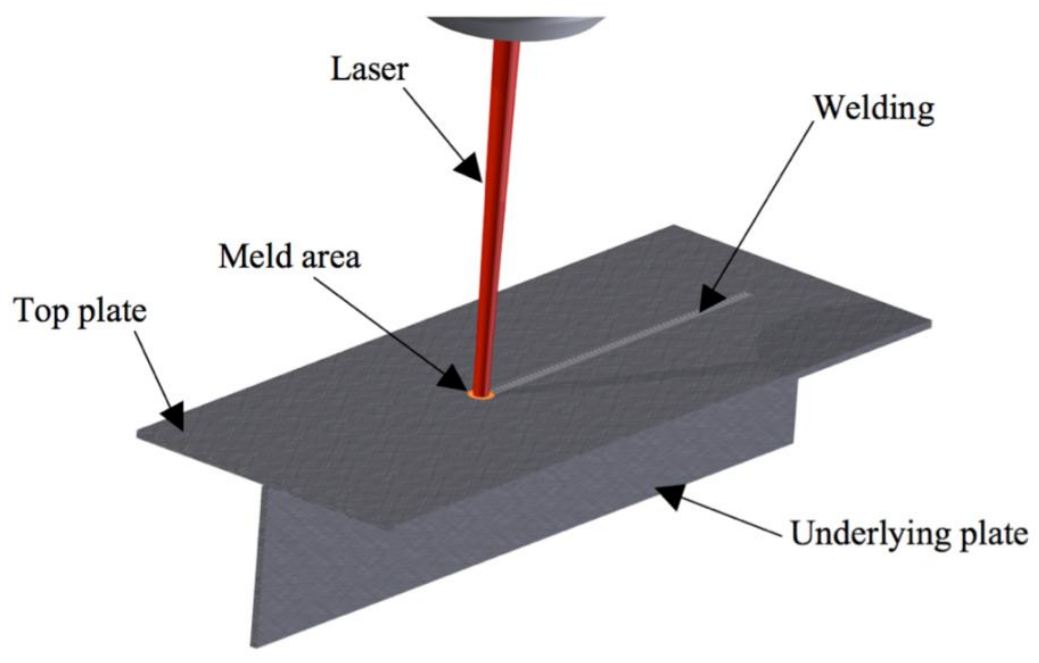

Figure 1. Illustration of the keyhole laser welding method in T-joints.

In the keyhole laser welding method, the top plate is penetrated with laser such the heat input is added to the underlying plate. Hereby, the liquid material in the heated zone will interweave and, thus, create the joint. When a welding is added 
to a structure, it affects the material at both the melted area and the area next to the welding, known as the heat-affected zone (HAZ). It is well known that the HAZ is of interest with regards to the durability of welded joints. However, when using laser welding, higher temperature gradients occur compared to conventional welding methods. These higher temperature gradients affect the joint, often by reduction of the durability.

In this laser welding process, metallurgical transformations, which alter, i.a., the fatigue and fracture properties of the affected material (Müller-Bollenhagen et al., 2010; Jayaprakash et al., 2004; Rodríguez-Martínez et al., 2013), can be triggered. In stainless steel AISI304, this transformation occurs under certain circumstances; primarily when the material temperature is below 50 degrees Celsius (Rodríguez-Martínez et al., 2013). However, it is the impact from the welding that causes the transformation. In particular, accumulated stresses and/or deformations can yield a transformation from austenitic to martensitic phase (Kirk et al, 1999). The thermal variations produce no metallurgical changes in AISI304 (Roth et al., 2010; Mostafa et al., 2012), but the welding process can accumulate residual stresses that can trigger metallurgical transformations (Li et al., 2014; Mostafa et al., 2012; Mitra et al., 2004). In some cases, the residual stress level is beyond $\sigma_{0.2}$ in the welded region due to the asymmetric cooling of the structure. Consequently, plastic strains are introduced, enabling activation of metallurgical transformation in the material (Ashok et al., 1989; Paulo et al., 2013). This metallurgical transformation can only occur in a specific temperature interval. For instance, if examining a thin plate made from AISI304, the temperature interval is about 40-50 degrees Celsius, thus providing a measure by which the quantity of transformation can be controlled. This is documented in (Li et al., 2014; Mostafa et al., 2012; Smaga et al., 2008) where a significant temperature rise due to adiabatic heating suppressed the transformation.

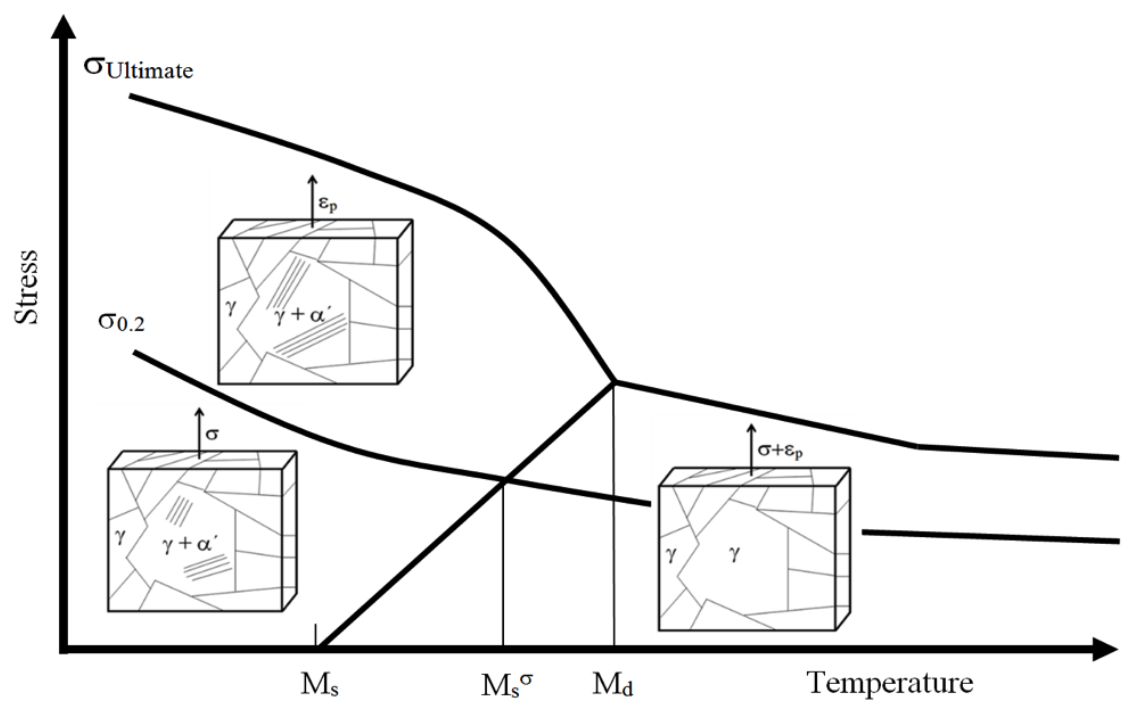

Figure 2. STT and DTT diagram of the $\gamma-\alpha^{\prime}$ transformation, where $\gamma$ and $\alpha^{\prime}$ is austenitic and martensitic structure.

Figure 2 shows the correlation of Stress-Temperature-transformation (STT) and Deformation-Temperature -Transformation (DTT). Md is the maximum temperature at which transformation by deformation occurs, and Ms is the transformation start temperature. At the Ms $\sigma$ temperature, the martensite transformation occurs when the stress level is above $\sigma_{0.2}$. For stainless steel, Ms $\sigma$ is between -10 and 50 degrees Celsius (Roth et al., 2010).

Since the transformation from austenite to martensite can result in significant degradations of fatigue and fracture properties of steel material, multiple methods have been developed to estimate the volume of generated martensite concentration. In the present study, four of such methods, namely Lichtenegger and Bloech (LB1) etching, Vickers hardness, ferritescope, and x-ray diffraction (XRD), are utilized to quantify the amount of introduced martensite in laser-welded AISI304 joints. As described in details in Section 3, each of the methods adds information about the concentration of martensite, thus by employing these four methods instead of just one, the reliability of the martensite concentration estimation is improved significantly. If the estimation is based on one method, it can be imprecise since each method has inherent shortcomings. For instance, the ferritescope measures the magnetic elements and therefore it cannot distinguish between martensite and ferrite elements in the welding.

The present study will investigate the martensite concentrations of the base material, welded zone and an oscillation load influence on the amount of martensite. The scope is to identify which influence the metallurgical changes has on the fatigue and fracture properties. 


\section{Experimental Procedure}

In the experimental work, specimens cut out mechanically from a $1 \mathrm{~mm}$ thick AISI304 stainless steel plate are utilized. The chemical composition is determine by spectroscopy and the result is; $0.036 \mathrm{C}, 0.42 \mathrm{Si}, 1.28 \mathrm{Mn}, 0.031 \mathrm{P}, 0.0010 \mathrm{~S}$, $18.21 \mathrm{Cr}, 8.30 \mathrm{Ni}$, and $0.050 \mathrm{~N}$.

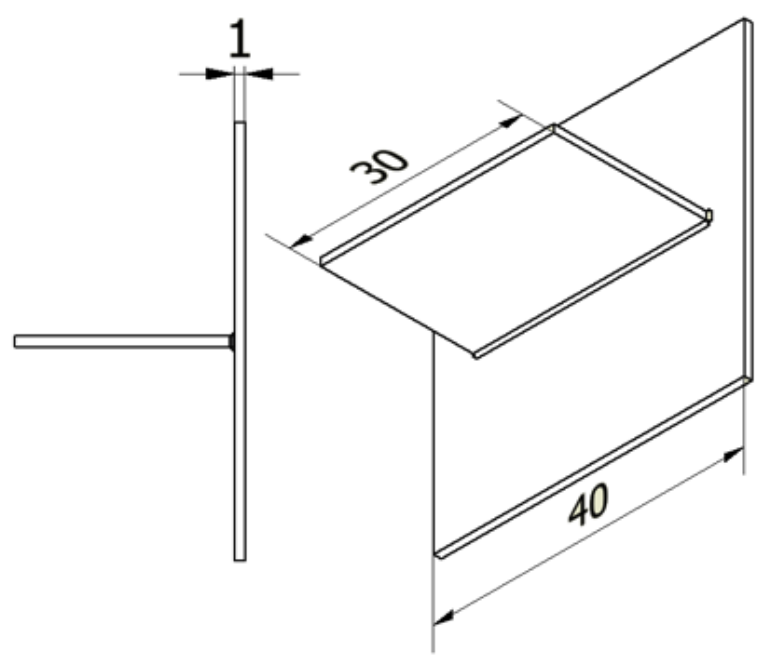

Figure 3. Sketch of specimen used in the experiments.

In figure 3, a sketch of the specimens is shown. The welding was carried out with a carbon dioxide Nd:YAG laser, which penetrates the surface with a spot size of $3 \mathrm{~mm}$. The power input is $4 \mathrm{~kW}$, with the laser head moving with a speed of $200 \mathrm{~mm} / \mathrm{min}$.

As stated in the introduction, the transformation from austenitic to martensitic phase can only occur in the specific temperature interval, [Ms;Md] (Kirk et al, 1999; Lin, et al., 2007; Müller-Bollenhagen et al., 2010). Ms and Md are calculated with Eq. (1) and Eq. (2).

$$
\begin{aligned}
& \mathrm{M}_{\mathrm{s}}\left({ }^{\circ} \mathrm{C}\right)=502-810(\% \mathrm{C})-1230(\% \mathrm{~N})-13(\% \mathrm{Mn})-30(\% \mathrm{Cr})-12(\% \mathrm{Ni})-54(\% \mathrm{Cu})-46(\% \mathrm{Mo}) \\
& \mathrm{M}_{\mathrm{d}}\left({ }^{\circ} \mathrm{C}\right)=413-462(\% \mathrm{C}+\% \mathrm{~N})-9.2(\% \mathrm{Si})-8.1(\% \mathrm{Mn})-13.7(\% \mathrm{Cr})-9.5(\% \mathrm{Ni})-18.5(\% \mathrm{Mo})
\end{aligned}
$$

Evidently, the content of $\mathrm{C}$ and $\mathrm{N}$ has the highest influence on the martensite trigger temperature. In this study, Ms and Md define when the transformation occurs.

\subsection{LB1 Etching}

The LB1 etching method facilitates observation of numerous metallurgical phenomena (Alexander et al., 2012). When etching AISI304, especially two of these phenomena are of interest namely transformation-induced-plasticity (TRIP), which is martensite introduced by plasticity, and twinning-induced-plasticity (TWIP) (Roth et al., 2010). It can be challenging to distinguish between TRIP and TWIP in a microscope view. This is exemplified in figure 4 where three metallurgic compositions, TRIP, TWIP, and austenite, are presented. Clearly, judgments are necessary to achieve satisfactory outline of the microscope view. However, etching will give an appraisal of the quantity of austenitic, martensitic and ferrite phase (Paulo et al., 2013). Etching should be conducted immediately after mixing to ensure that the dyeing will be sufficient. 


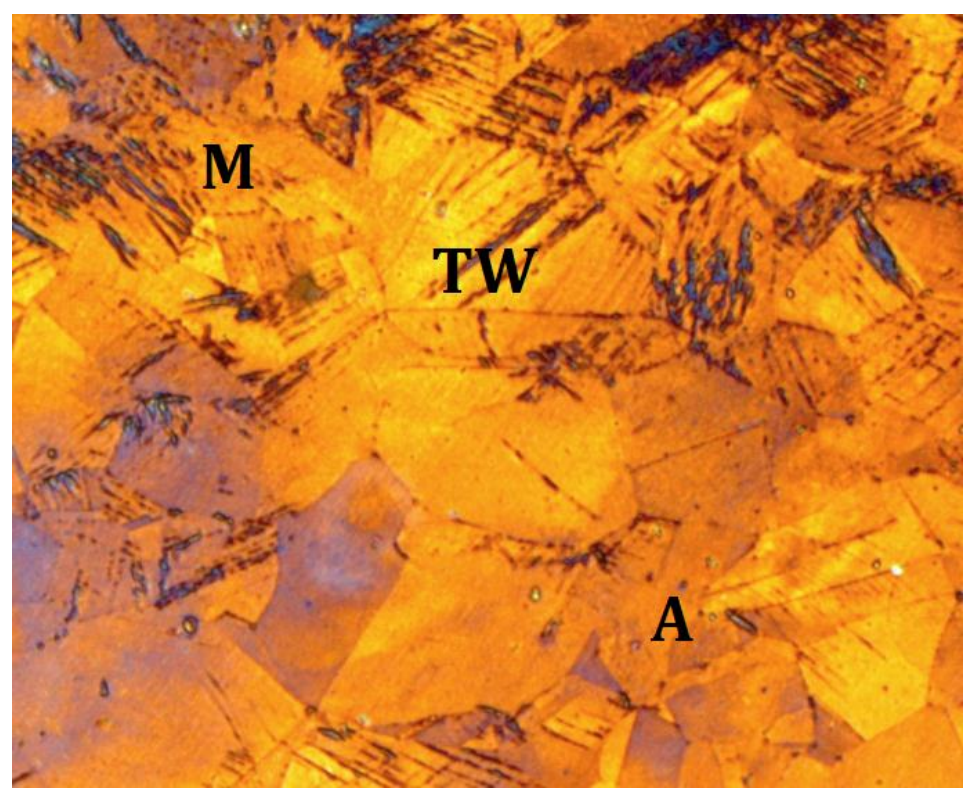

Figure 4. Etching of AISI304 with LB1. Austenite (A), martensite (M) and TWIP (TW) formation are present.

\subsection{Vickers Hardness Methods}

The hardness of the material in the HAZ and the far field are measured by Vickers hardness. A concentration of martensitic phase will yield a harder material, hence facilitating location of this concentration. Three locations on the joint are measured; one in the center of the welding plus one $1 \mathrm{~mm}$ and one $5 \mathrm{~mm}$ from the center of the welding. The hardness is then obtained as the mean of eight tests at each measurement point. By doing so, reliable results are obtained in a simple way.

\subsection{Ferrite Scope}

The ferrite scope measures the amount of ferrite magnetic elements in the welded material (Alexander et al., 2012). The measurements take place in two points, as indicated in figure 5. The results in these points are then converted to an equivalent concentration of martensitic phase via Eq. (3).

$$
\text { Vol } \% \text { martensite }=1.75 \cdot \text { Ferritescope result }
$$

As mentioned in the introduction, the ferritescope method has a shortcoming because it cannot distinguish between different magnetic elements. This is an issue in the present study since AISI304 can contain two magnetic elements, in the form of martensite and $\delta$-ferrite.

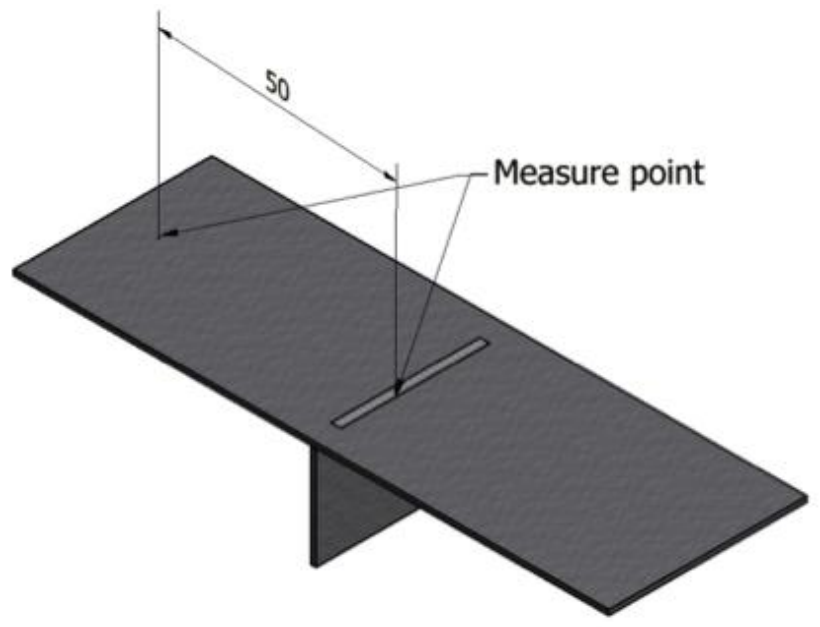

Figure 5. Ferritescope measurement points on test specimen. The point at the welding is denoted center, while the other point is denoted far field. 
The presence of the latter in the HAZ is generally increased with high cooling rate (Eichelman et al., 1952). The highest concentration of $\delta$-ferrite is located in the zone between the melted and non-melted material (Prohaska et al., 2012). Consequently, results from other methods, e.g. LB1, are a necessity to quantify the amount of martensite.

\subsection{X-ray Diffraction}

XRD measures the reflection from the examined material. Hereby, the distance between the atoms can be determined and the crystal types identified. This method is based on Bragg's Law of Diffraction, which measures the average spacing between layers or rows of atoms (Li et al., 2014; Ashok et al., 1989).

In this study, Philips Xpert 3kV Cu X-Ray Diffraction equipment is used to examine two types of specimens; welded and non-welded. Strain has been introduced to the non-welded specimens in accordance with four levels, namely $0 \%$, $10 \%, 20 \%$ and $25 \%$ elongation. By doing so, the results can be used to analyse strain-introduced transformation in the form of martensitic phase (Kurc et al., 2013; Jayaprakash et al., 2004).

\section{Experimental results}

The stress and deformation transformation levels of martensite are calculated by means of Eq. (1) and (2), resulting in $\mathrm{M}_{\mathrm{s}}=-236^{\circ} \mathrm{C}$ and $\mathrm{M}_{\mathrm{d}}=42.5^{\circ} \mathrm{C}$, respectively. The $\mathrm{M}_{\mathrm{s}}$ is so low that no stress-induced transformation occurs in the weld. Since $\mathrm{M}_{\mathrm{d}}=42.5^{\circ} \mathrm{C}$, the cooling subsequent to the welding procedure can introduce small amounts of DTT by thermal deformation. The transformation can only occur in the temperature interval from $42.5^{\circ} \mathrm{C}$ to the surrounding temperature, thus the transformation level seems to be low such only a small concentration of martensite can be developed in the welded area. In the following, the four-presented methods for detecting metallurgical changes will be applied to examine the martensite concentration.

\subsection{Application of LB1 Etching}

The amount of transformation can be detected with LB1 etching (Talonen et al., 2004). The etching is used at a section cut of the welding, and hereby a microscope photograph like the one in figure 6 can be established. The blue and brown colors in figure 6 indicate martensite and austenite concentrations, respectively. Evidently, martensite concentrations are introduced in the melted area and in the middle of the plate. The highest concentration of martensite is in the joint between the two components. Additionally, the microscope photograph in figure 6 also shows a concentration of martensite at the cut surface and along the rolling lines in the middle of the plate. The transformations in these areas are caused by plastic deformations in the manufacturing process.

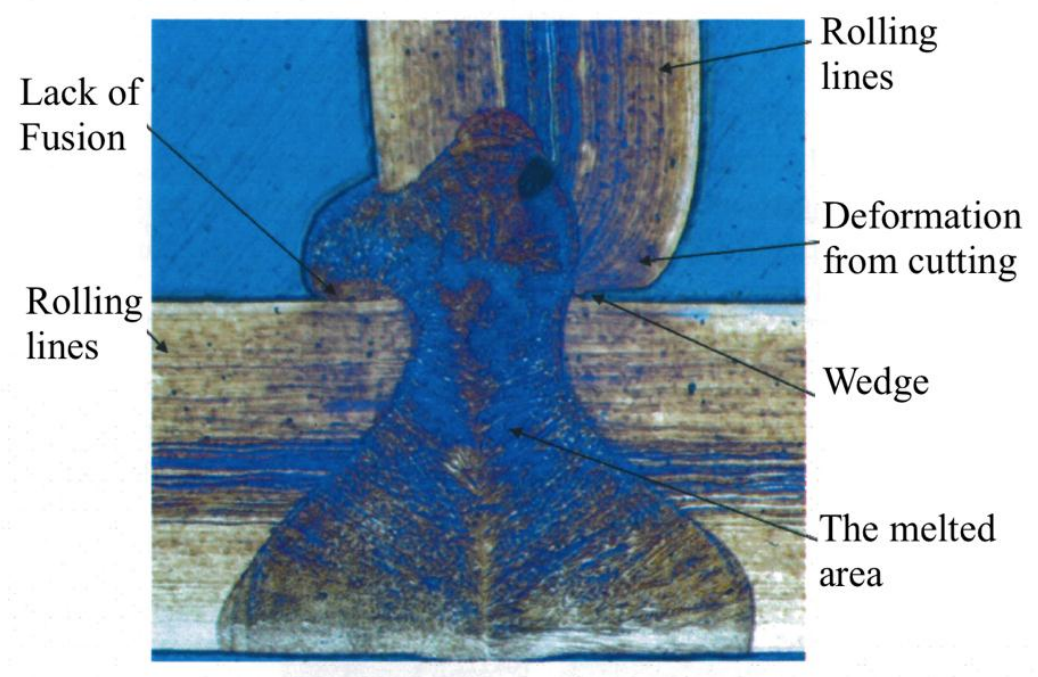

Figure 6. Etching of AISI304 with LB1 with indication of austenite, martensite and TWIP formation.

\subsection{Application of Vichers Hardness}

In Table 1, the results from the Vickers hardness test are presented. Here, it is seen that the maximal hardness is found at the center of the weld, with a value of $200 \mathrm{HV}$. The hardnesses found in the two adjacent points are $185 \mathrm{HV}$ and $183 \mathrm{HV}$, respectively. The findings clearly indicate martensite in the welded region. 
Table 1. Vickers hardness in specific distances from the welding center.

\subsection{Application of Ferritescope}

\begin{tabular}{c|c}
\hline Distance $(\mathrm{mm})$ & Hardness $(H V)$ \\
\hline 0 & 200 \\
1 & 185 \\
5 & 183 \\
\hline
\end{tabular}

The concentration of ferromagnetic elements is determined through a ferritescope. In the far field area of the welded specimen, a concentration of 0.19-0.2 ferromagnetic elements is found, while the level in the center is 0.5-0.66. The other welded specimen, which additionally has been loaded with an oscillation load, has a concentration of 0.2-0.22 in the far field area and a concentration of 0.83-0.97 in the center. By substituting these results into Eq. (3), the corresponding percentage martensitic phase concentrations are calculated. In Table 2, these calculated concentrations are given.

Table 2. Results of percentage martensitic phase concentration found through ferritescope test of two different specimens.

\begin{tabular}{ccc}
\hline Ferritescope results & Welded & Welded and loaded $(H V)$ \\
\hline Far Field & $0.34 \%$ & $0.37 \%$ \\
Center & $1.00 \%$ & $1.60 \%$ \\
\hline
\end{tabular}

Evidently, the amount of martensitic phase is $0.66 \%$ higher in the center than in the far field for the welded specimen. This difference increases to $1.23 \%$ when examining the welded and loaded specimen.

\subsection{Application of X-ray Diffraction}

In the XRD study, references are generated for comparison with the welded specimens. The references are composed of, respectively, undeformed (i.e. untreated) and deformed non-welded specimens of the base material, AISI304. As seen in figure 7, where the XRD test results for the reference specimens are presented, the deformations lead to significant decreases in the intensity of $\gamma(311)$ and significant increases in the intensity of $\gamma(111)$. Furthermore, it is observed that the intensities of $\alpha^{\prime}(200)$ and a'(220) increase slightly as a consequence of deformation.

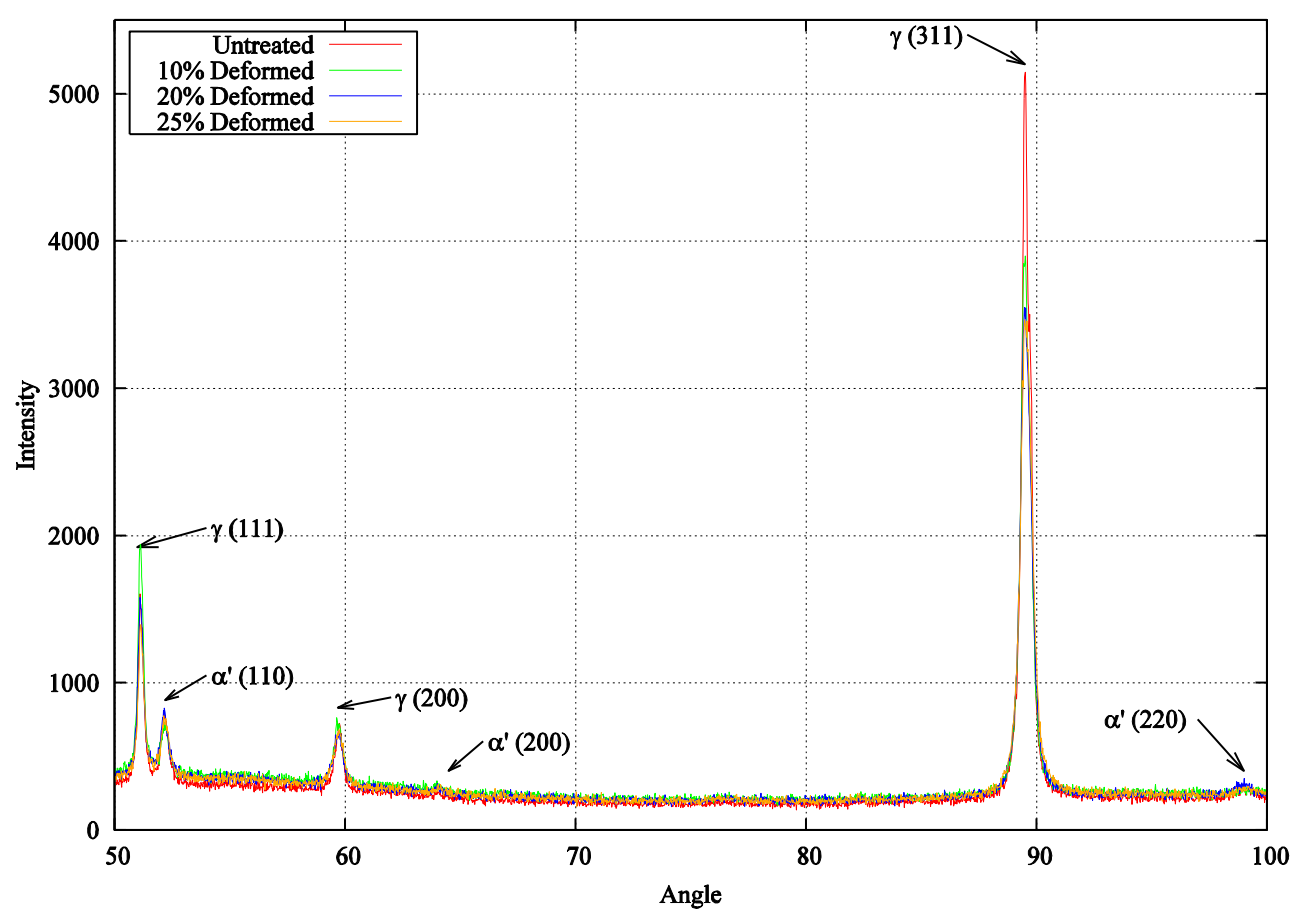

Figure 7. XRD test results showing $\gamma$ and $\alpha^{\prime}$ phase in references, i.e. untreated and deformed AISI304 specimens 
In figure 8, the results obtained in two analogous XRD tests of the laser-welded specimens are shown. Since the results indicate consistency, only one set of test results is compared directly to the reference specimens, see figure 9.

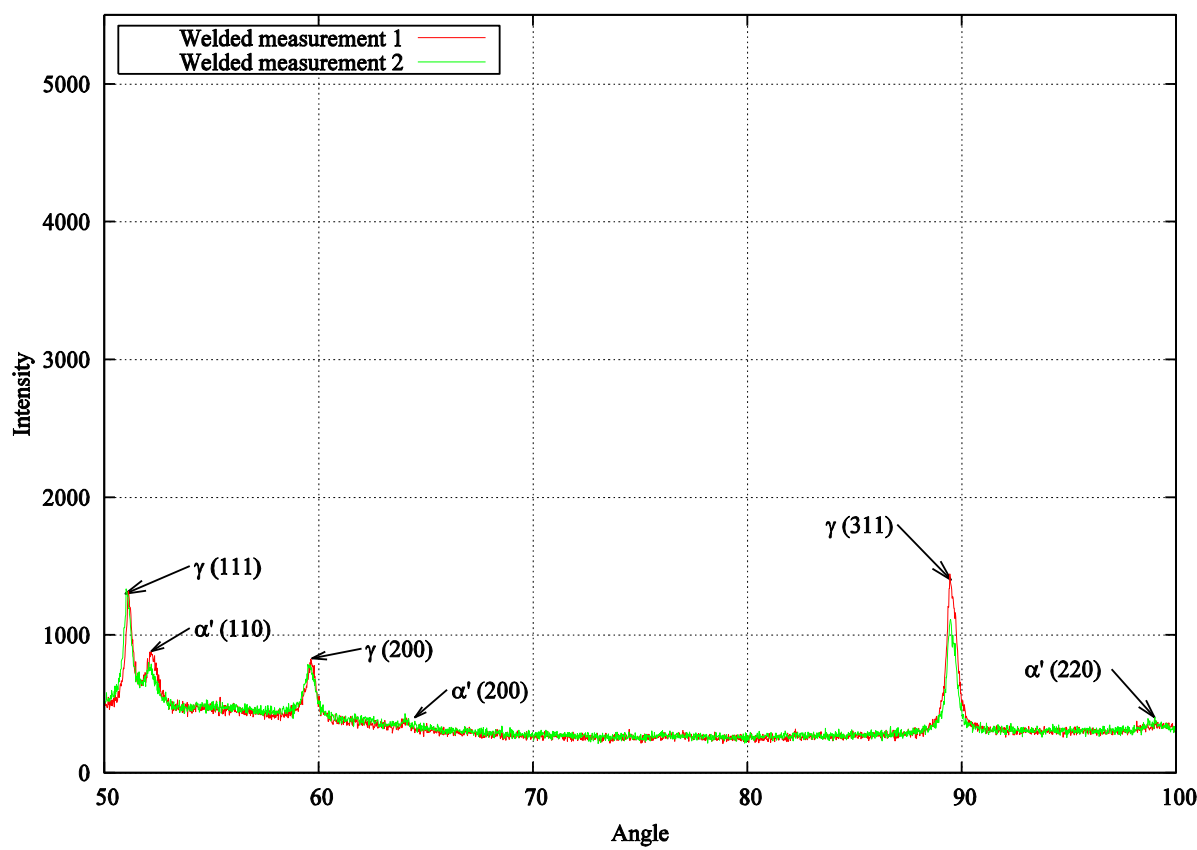

Figure 8. XRD show $\gamma$ and $\alpha^{\prime}$ phase in welded specimens of AISI304

When inspecting figure 9, it is evident that the intensities of $\gamma(111)$ and $\gamma(311)$ are lower in the welded specimen compared to the untreated and deformed ones. This is due to disorder from the welding process. The intensity of $\alpha^{\prime}(200)$ is, however, highest in the welded specimen and lowest in the untreated, hence indicating a limited increase of martensite in the welded area. Regarding $\alpha^{\prime}(110)$, it is observed that the peak is wider for the welded specimen compared to the corresponding peaks for the other specimens. This indicates that a larger amount of $\alpha^{\prime}(110)$ is present in the welded specimen. The highest changes is $\gamma(311)$ between the welded material and the untreated material. For the remaining phases, i.e. $\alpha^{\prime}(220)$ and $\gamma(200)$, insignificant changes are introduced as a consequence of welding.

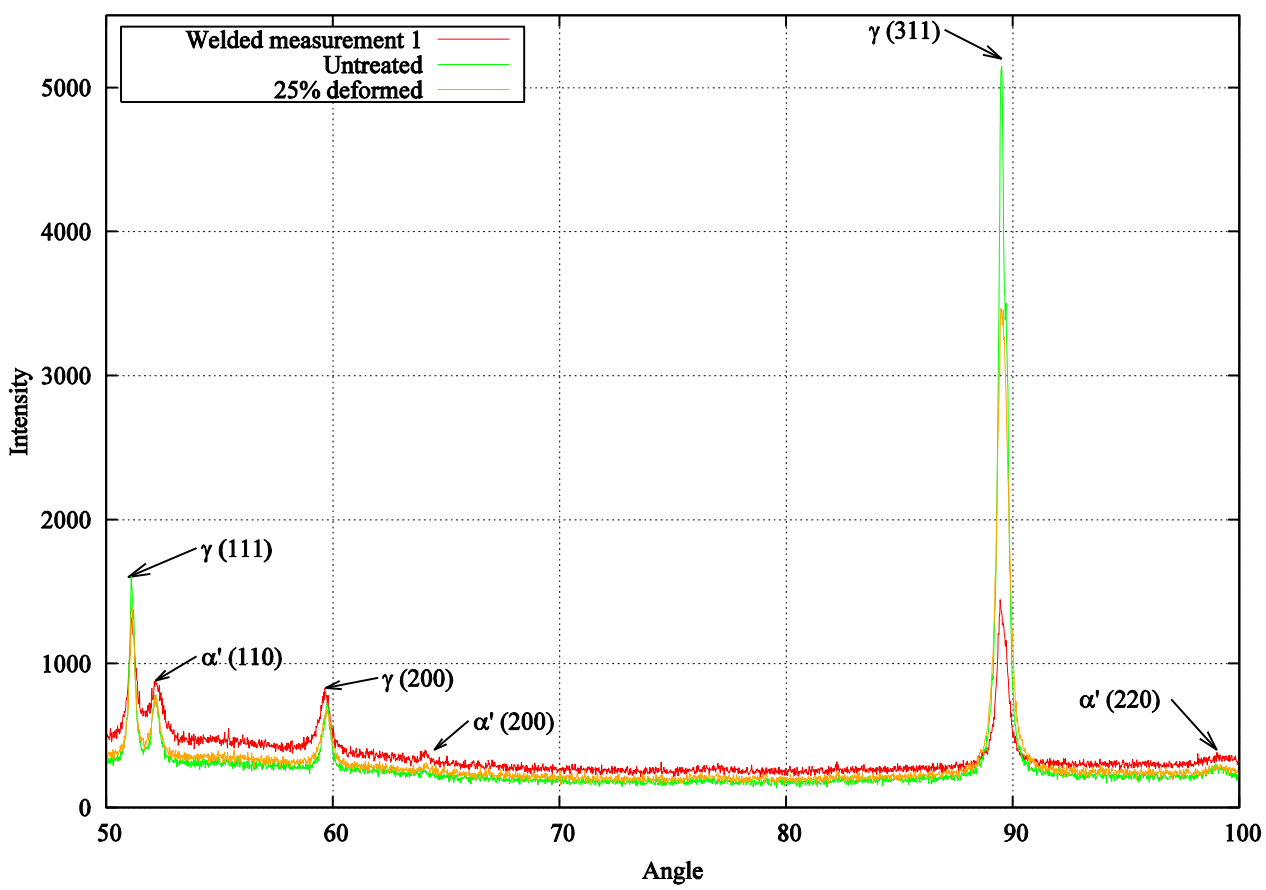

Figure 9. XRD test results showing $\gamma$ and $\alpha^{\prime}$ phase in welded, deformed, and untreated AISI304 specimens. 


\section{Conclusion}

In this study, laser welding-induced changes in the microstructure of AISI304 specimens are investigated experimentally. In particular, the concentrations of martensitic phase have been of interest. These concentrations have been quantified by use of four different methods, namely LB1 etching, ferritescope, $x$-ray diffraction (XRD), and Vickers hardness, and hereby the following results have been obtained:

- LB1 etching shows a concentration of martensitic phase in the laser-welded material.

- The Vickers hardness test shows a significant increase of the hardness in the welded area. This indicates presence of a limited concentration of martensite in the welded area.

-The ferritescope result is translated to percent- tage martensitic phase concentration. In the welded specimen, the amount of martensitic phase is approximately $1 \%$ and $0.3 \%$ in the welded zone and at the far field, respectively. By adding an oscillation load the martensitic phase concentration increases to $1.6 \%$ in the welded zone and $0.35 \%$ at the far field.

-The XRD test shows a disorder in the microstructure in the melted material. Small increases in a' (110) and a' (200) are observed, hence indicating a limited increase of martensite.

The summative conclusion is that the laser welding- induced increase in martensite is less than $1 \%$, thus the laser welding method has limited effect on the fatigue parameter.

\section{References}

Li, Xibin, Lu, Fenggui, Cui, Haichao, Tang, Xinhua, \& Wu, Yinhua. (2014). Numerical modeling on the formation process of keyhole-induced porosity for laser welding steel with T-joint. The International Journal of Advanced Manufacturing Technology.

Morteza, Z., Reza bateni, M., Poladi, A., \& Jerzy, A. S. (2007). The formation of martensite during wear of AISI 304 stainless steel, Wear, 674-678. http://dx.doi.org/10.1016/j.wear.2007.01.107

Müller-Bollenhagen, C., Zimmermann, M., \& Christ, H. J. (2010). Adjusting the very high cycle fatigue properties of a metastable austenitic stainless steel by means of the martensite content. Procedia Engineering, 2(1), 1663-1672. http://dx.doi.org/10.1016/j.proeng.2010.03.179

Jayaprakash, Sumanth Kumar, J., Sivaprasad, K., \& Ganesh Sundara Raman, S. (2004). EFFECT OF GRAIN SIZE ON FRETTING FATIGUE BEHAVIOUR OF AISI 304 STAINLESS STEEL. International Symposium of Research Students on Materials Science and Engineering, pp. 1-8.

Rodríguez-Martínez, J. A., Rusinek, A., Pesci, R., \& Zaera, R. (2013). Experimental and numerical analysis of the martensitic transformation in AISI 304 steel sheets subjected to perforation by conical and hemispherical projectiles. International Journal of Solids and Structures, 50(2), 339-351.

Kirk, D., \& Payne, N. J. (1999). Transformations Induced in Austenitic Stainless Steels by Shot Peening, in ICSP, WARSAW, POLAND, pp. 15-22.

Roth, I., Kübbeler, M., Krupp, U., Christ, H. J., \& Fritz, C. P. (2010). Crack initiation and short crack growth in metastable austenitic stainless steel in the high cycle fatigue regime. Procedia Engineering, 941-948. http://dx.doi.org/10.1016/j.proeng.2010.03.102

Mostafa, E., Abbas, Z. H., \& Ali, M. (2012). An investigation into the mechanical behavior of a new transformation-twinning induced plasticity steel. Materials \& Design, 39, 279-284.

Mitra, A., De, P. K., Bhattacharya Sr, D. K., Srivastava, P. K., \& Jiles, D. C. (2004). Ferromagnetic Properties of Deformation-Induced Martensite Transformation in AISI 304 Stainless Steel. Metallurgical and Materials Transactions A, 35(2), 599-605.

Ashok, K., \& SInghal, L. K. (1989). Effect of Strain Rate on Martensitic Transformation during Uniaxial Testing of AISI-304 Stainless Steel. Metallurgical Transactions A, 20A, 2857-2859.

Paulo, R. M. (2013). Metallurgy and materials, INOX 2010 - 10th Brazilian Stainless Steel Conference, pp. 221-225.

Smaga, M., Walther, F., \& Eifler, D. (2008). Deformation-induced martensitic transformation in metastable austenitic steels. Materials Science and Engineering: A, 483-484, 394-397.

Chi-Ming, Lin, Gen-Huey, Lai, Yu-Che, Chen, Yung-Tse, Chang, \& Weite Wu. (2007). Characterization and Mechanism of 304 Stainless Steel Vibration Welding. Materials Transactions, 48(9), 2319 to 2323. https://www.jim.or.jp/journal/e/pdf3/48/09/2319.pdf 
Alexander, K. A., Andreas, W., Steffen, W., \& Piotr, R. S. (2012). STT and DTT Diagrams of Austenitic Cr-Mn-Ni As-Cast Steels and Crucial Thermodynamic Aspects of $\gamma \rightarrow \alpha^{\prime}$ Transformation. Steel research international, 83(6), 576-583.

Eichelman Jr, G. H., \& Hull, F. C. (1952). The Effect of Composition on the Temperature of Spontaneous Tranformation of Austenite to Martensite in 18-8 Type Stainless Steel. Transactions of A.S.M, 45, 77-95.

Prohaska, M., Panzenbowck, M., Anderl, H., \& Kordasch, W. (2012). Influence of chemical composition and microstructural parameters on speed of sound of various materials used for high-pressure applications, in 18th World Conference on Nondestructive Testing, Durban, South Africa, 16-20 April 2012.

Li, Yongfeng, Bu, Fuming, Kan, Wenbin, \& Pan, Hongliang. (2012). Deformation-Induced Martensitic Transformation Behavior in Cold-Rolled AISI304 Stainless Steels. Materials and Manufacturing Processes, 28(3), 256-259.

Kurc, A., \& Stoklosa, Z. (2013). The effect of $\left(\gamma \rightarrow \alpha^{\prime}\right)$ phase transformation on microstructure and properties of austenitic Cr-Ni steels. Archives of Materials Science and Engineering, 41(2), 85-94.

Talonen, J., Aspegren, P., \& Hnninen, H. (2004). Comparison of different methods for measuring strain induced $\alpha$-martensite content in austenitic steels. Materials Science and Technology, 1506-1512.

\section{(cc) EY}

This work is licensed under a Creative Commons Attribution 3.0 License. 